did not receive this letter until May I4, when he sought in vain for the comet. Pingré who wrote before any suspicion had been raised with respect to D'Angos, attributed this to its having in the interval receded to too great a distance from the earth, or having attained too great south declination. It appears that Messier did not receive any further observations from Malta, but D'Angos some time afterwards communicated to him elements of the orbit, calculated by himself, and it was to be presumed with the aid of further positions. The observatory at Malta was burnt at a subsequent period, and the whole of the papers, \&c., of D'Angos were stated to have fallen a prey to the flames, so that it was supposed in France that the observations were irrecoverably Iost. Burckhardt had endeavoured by successive hypotheses to extract some idea of the nature of the orbit from the two rough observations which he had received, and as his results differed widely from those of D'Angos, and even the elements of the latter did not represent these observations, Delambre, at the instance of Burckhardt, wrote for further particulars. In reply, D'Angos stated that he had only saved from the fire his meteorological journal, in which, under date April 22, was mentioned an observation of the zodiacal light, without any reference to the comet, whence he concluded that on this date the latter was no longer visible.

This assertion will appear a most extraordinary one when it is stated that so far from the observations being lost, they had appeared in a memoir drawn up by D'Angos himself, in a periodical conducted by Bernoulli and Hindenberg, entitled-Leipziger Magazin fïr reine und angewandte Mathematik, Leipzig, 1786, where they were discovered by Olbers, as he mentions in a letter to Encke, inviting his discussion of them. Positions of the comet in longitude and latitude are there given for fourteen nights between April Io and May r, and they are followed by the elements of the orbit, which D'Angos says he had calculated from them.

Zach in 1812 had suspected that the observations of the second comet of 1784 were imaginary, and had suggested that the orbit should be omitted from the catalogues, but he adds as he had only great probabilities and moral, not mathematical, proofs to support his view, he did not insist upon it. To provoke an explanation, however, he states he had enveloped "ce mystère d'iniquité " in a problem in vol. iii. of his Correspondance Astronomique, where he printed a series of positions of a body, which he invited his readers to explain, and which puzzled Olbers and Bessel who failed, like others, to discover Zach's meaning. Burckhardt also on receiving intimation from Olbers of his having brought to light what purported to be the observations of D'Angos, remarked upon the importance attaching to the circumstance, since it might lead to proof that they had been fabricated.

It remains to describe in a future note or notes, the results of Encke's investigation and of later inquiries relative to the comet of D'Angos.

\section{PROF. SYLVESTER ON TEACHING AND "RESEARCHING"}

$\mathrm{N}$ the address of Prof. Sylvester at the Johns Hopkins University, to which we have already referred, he spoke as follows on the above subject :-

Let me take this opportunity of making my profession of faith on a subject much mooted at the present day, as to whether the highest grade of university appointments should be conferred with or without the condition of teaching annexed.

I hesitate not to say that, in my opinion, the two functions of teaching and working in science should never be divorced. I believe that none are so well fitted to impart knowledge (if they will but recognise as existing, and take the necessary pains to acquire, the art of presentation) as those who are engaged in reviewing its methods and extending its boundaries-and I am sure that there is no stimulus so advantageous to the original investigator as that which springs from contact with other minds and the necessity for going afresh to the foundations of his knowledge, which the work of teaching imposes upon him. I look forward to the courses of lectures that $I$ hope to deliver in succession within the walls of this university as marking the inauguration of a new era of productivity in my own scientific existence; nor need I consider any subject too low (as it is sometimes foolishly termed) for me to teach, when I remember to have seen the minutes of the conversation held between the delegates of the Convention, at the time of the French Revolution, and the illustrious Lagrange, the son of the pastry-cook of Turin, possibly the progenitor of the Marquis Lagrange, of turf celebrity (Citoyen Lagrange, as he is styled in the record), who, when asked what subject he would be willing to profess for the benefit of the community, answered meekly, "I will lecture on Arithmetic."

At this moment I happen to be engaged in a research of fascinating interest to myself, and which, if the day only responds to the promise of its dawn, will meet, I believe, a sympathetic response from the Professors of our divine Algebraical art wherever scattered through the world.

These are things called Algebraical Forms. Prof. Cayley calls them Quantics. These are not, properly speaking, Geometrical Forms, although capable, to some extent, of being embodied in them, but rather schemes of processes, or of operations for forming, for calling into existence, as it were, algebraic quantities.

To every such Quantic is associated an infinite variety of other forms that may be regarded as engendered from and floating, like an atmosphere, around it-but infinite in number as are these derived existences, these emanations from the parent form, it is found that they admit of being obtained by composition, by mixture, so to say, of a certain limited number of fundamental forms, standard rays, as they might be termed in the Algebraic Spectrum of the Quantic to which they belong. And, as it is a leading pursuit of the Physicists of the present day to ascertain the fixed lines in the spectrum of every chemical substance, so it is the aim and object of a great school of mathematicians to make out the fundamental derived forms, the Covariants and Invariants, as they are called, of these Quantics.

This is the kind of investigation in which $I$ have, for the last month or two been immersed, and which I entertain great hopes of bringing to a successful issue. Why do I mention it here? It is to illustrate my opinion as to the invaluable aid of teaching to the teacher, in throwing him back upon his own thoughts and leading him to evolve new results from ideas that would have otherwise remained passive or dormant in his mind.

But for the persistence of a student of this University in urging upon me his desire to study with me the modern Algebra I should never have been led into this investigation; and the new facts and principles which I have discovered in regard to it (important facts, I believe,) would, so far as I am concerned, have remained still hidden in the womb of time. In vain I represented to this inquisitive student that he would do better to take up some other subject lying less off the beaten track of study, such as the higher parts of the Calculus or Elliptic Functions, or the theory of Substitutions, or I wot not what besides. He stuck with perfect respectfulness, but with invincible pertinacity, to his point. He would have the New Algebra (Heaven knows where he had heard about it, for it is almost unknown in this continent), that or nothing. $I$ was obliged to yield, and what was the consequence? 
In trying to throw light upon an obscure explanation in our text-book, my brain took fire, I plunged with requickened zeal into a subject which I had for years abandoned, and found food for thoushts which have engaged my attention for a considerable time past, and will probably occupy all my powers of contemplation advantageously for several months to come.

\section{OUR INSECT FOES}

$A^{N}$ $\mathrm{N}$ important conference was held at the Society of Arts on Tuesday afternoon on the subject of insects injurious to agriculture and methods of stamping them out. Its origin was a proposition by Mr. Andrew Murray (who has had the arrangement of the collection of ecoincmic entomology made by the Science and Art Depart. ment), which he laid before the Lord President of the Council. The proposition was printed by order of the president, and copies were sent to the agricultural societies and chambers of agriculture of the country. After the proposition had been before them for two months and there was no indication of any notice being taken of it, it was arranged that a conference of delegates of agricultural societies should be held at the Society of Arts. The Duke of Buccleuch, K.G., took the chair, and there were present representatives of the Scottish, Cheshire, Warwick, Hampshire, and Banbury Chambers of Agriculture; the Farmers' Club, Dr. Maxwell Masters, representing the president of the Royal Society, Prof. Voelcker (chemist to the Royal Agricultural Society), Mr. Sewell Reed, M.P., \&c. The conference was opened by a paper read by Mr. Murray.

The paper commenced by assuming as an axiom that, besides the occasional great injury done by insects, by which whole districts are ravaged, a continual drain is constantly kept up by then, which constitutes a very perceptible percentage of deduction from the cultivators' profits ; and, further, that where this loss can be prevented at less cost than the loss it occasions, it should be prevented.

It next maintained that, if we wish to rid a district or a country of an injurious insect, to be effective, any attempt to do so must be simultaneous and combined, for to what purpose would it be if one man cleared his farm if his neighbour did not clear his; or if the one cleared his one year, and the other cleared his another? A central authority, therefore, is needed to secure united action.

It next considered the various ways in which the insects injurious to agriculture might be extirpated. The first, the simplest, the most powerful, and the most efficient of these is county or district rotation of cropping. Farmers know well enough the advantage of a rotation of cropping (or its equivalent) on their own farms. By long-continued growth of the same crop on the same land the soil becomes exhausted of some of the elements necessary for the proper development of that kind of crop, and a change of crop brings other elements into use, and relaxes the femand upon those that have been too much drawn upon.

Exactly the converse of this takes place with regard to certain insects. The great majority of vegetable-feeding insects do not feed on all kinds of plants indiscriminately; most of them are restricted to one kind of plant, and if by cultivation of that plant its numbers are enormously in. creased, so will naturally be the number of the insects that feed upon it ; while, if we should cease to grow that plant, the number of the insects would correspondingly diminish. Thus, for instance, if a district is almost entirely in pasture, there will be very few wheat-feeding insects in it, but if it is turned into a wheat country they will be myriads. If these numbers reach such a pitch as to deteriorate the crops the remedy is plain. Change the rotation, and grow some other crop instead of wheat.
Most of the wheat insects are only annuals. If they could be banished for one year they would be banished entirely, or until re-introduced. Now, if there were a controlling authority, what would be easier than to say to the farmers, "Gentlemen, in the common interest you will substitute barley for wheat in your next year's rotation." The insect, deprived of its proper nidus, must then either lay its eggs in an unsuitable place where they will perish, or have recourse to the pasture fields for Triticum referus, or other suitable grasses. By this, of course, the fly would not be exterminated, but its numbers would be so reduced as to render it comparatively harmless, at all events for a time, when, if it again reappeared in force, the same means of defence would be resorted to. $\mathrm{Nay}$, it might be so arranged that two or more counties might brigade themselves together, so as to establish a permanent see-saw by which they should play into each other's hands. But no single man can carry out such a rotation. He may try it upon his own fields, but they will be replenished continually from the fields of his neighbours, unless they at the same time are compelled to follow the same rotation.

Mr. Murray then went over the various other means of extirpation-picking and burning infected plants, the collecting caterpillars, poisons, and local remedies, in relation to which he drew attention to the destruction of what are called ticks and lice upon sheep. Everyone knows how readily such vermin can be communicated by contact or even proximity, and it does seem a very hard case that a man, who has kept his flock clean by taking proper precautions, should be liable to have them infected by a neighbouring neglected flock, by stray sheep, or even by sheep passing along the road. It is said that, cateris paributs, the difference in value between a sheep that has been kept clean for the season and one that has been worried by vermin will be 205. If that is so it is a wonder that sheep farmers have not long since clamoured for some supervision.

At the conclusion of the paper the following resolution was put from the chair and carried :- "That thanks are due to the President and Lords of the Council for having brought the subject of insect damage under the consideration of the agricultural bodies of the kingdom."

Dr. Maxwell Masters moved the next resolution, and in doing so said he was charged to express the regret of the President of the Royal Society that he was unable to be present. He spoke of the great ignorance throughout the country on the subject of insect damage, and as an indication of the amount of damage done, said that half the time of the Scientific Committee of the Royal Horticultural Society was occupied with answering inquiries from all parts as to how to deal with insect foes. The resolution he moved was,- " That much of the loss occasioned by insects is preventible, and ought to be prevented." This was seconded by Mr. Maclagan, and carried.

Mr. Mechi then moved-" That it properly belongs to Government to provide the necessary means for protecting cultivators from this loss, as it is only by combined and simultaneous action over considerable districts that it can be effectually done, and Government alone possesses or can obtain the requisite means of enforcing such action."

Both Mr. Mechi in moving it and Prof. Voelcker in seconding it, spoke of the want of knowledge throughout the country on the subject. Mr. Sewell Reed urged it was not a question for government but for agricultural societies. The resolution was declared carried, though many hands were held up against it.

The last resolution was-"That the President and Lords of the Council and the Agricultural Societies of the United Kingdom be informed of the opinion of this Conference, and urged to take the subject at once into their consideration, with a view of providing a remedy," which, after a long discussion, was carried. 